\title{
The effect of mother's educational status on early initiation of breastfeeding: further analysis of three consecutive Nepal Demographic and Health Surveys
}

Pawan Acharya ${ }^{1 *}$ and Vishnu Khanal ${ }^{1,2}$

\begin{abstract}
Background: The World Health Organization recommends initiating breastfeeding within the first hour of birth. This study is aimed at assessing the effect of the mother's education on early initiation of breastfeeding.

Methods: Data from the Nepal Demographic and Health Surveys (NDHS) 2001, 2006 and 2011 were used which included 12,845 last born children born within 5 years before the surveys. Early initiation of breastfeeding was defined as the initiation of breastfeeding within the first hour after birth. Hierarchical modelling was used to ascertain the association of maternal education and early initiation of breastfeeding, after controlling for other covariates in a multiple logistic regression.

Results: Maternal education was associated with a higher likelihood of early initiation of breastfeeding in each survey. Pooled data analysis revealed higher odds of early initiation of breastfeeding among the mothers with primary education (adjusted odds ratio (OR) 1.24, $95 \%$ confidence interval (Cl): 1.09, 1.42) and secondary or higher education (OR: $1.6395 \%$ Cl: 1.42, 1.88). In the most recent NDHS 2011 survey, odds of early initiation of breastfeeding was higher among mothers with primary education (OR: 1.52; $95 \% \mathrm{Cl}: 1.21,1.91)$ and mothers with secondary or higher education (OR: 2.20; $95 \%$ Cl: 1.76, 2.76) compared to mothers with no education. Similarly, the odds of early initiation of breastfeeding was higher among mothers with secondary and higher education in the 2006 data (OR: 1.66; $95 \%$ Cl: 1.30, 2.12) and in 2001 (OR=1.30; $95 \%$ Cl: 1.00, 1.67).

Conclusions: As the association between a mother's educational status and her likelihood of early initiation of breastfeeding increases, long-term approaches to prioritising education for women and girls should be explored. In the short term, uneducated mothers should be targeted with breastfeeding promotion strategies such as counselling and peer education.
\end{abstract}

Keywords: Breastfeeding, Maternal educational status, Demographic and health survey, Nepal

\section{Background}

Globally, about $60 \%$ of child deaths are directly or indirectly linked to undernutrition. Two- thirds of child deaths are estimated to be attributed to improper feeding during the first year of life [1]. As the leading global health institution, the World Health Organization (WHO) has identified sub-optimal breastfeeding as a barrier to sustainable socioeconomic development and

\footnotetext{
* Correspondence: ac.pawan@gmail.com

${ }^{1}$ Nepal Development Society, Bharatpur, Nepal

Full list of author information is available at the end of the article
}

poverty reduction [1] and recommends initiating breastfeeding within the first hour after birth [2-4]. The first breast milk after delivery (colostrum) provides energy and immunity to newborn [5]. Delayed initiation of breastfeeding may lead to hypothermia [6]. A study has reported higher odds of neonatal mortality [pooled odds ratio (OR): 2.02, $95 \%$ confidence interval $(\mathrm{CI}): 1.40$, 2.93] among those who were breastfed after the first hour of birth compared to the children breastfed within the first hour after birth [7]. Similarly, a hospital based cross sectional study in Ghana reported an increased 
risk of infant mortality in the case of delayed initiation of breastfeeding. The study reported greater than a twofold risk (OR: 2.4, 95 \% CI: 1.69, 3.40) of mortality if the initiation was delayed for 1 day after birth [8]. In Nepal, the risk of infant mortality was found higher among those who were breastfed later than $24 \mathrm{~h}$ of birth (relative risk (RR): 1.41; 95 \% CI: 1.08, 1.86) [9].

Nepal has achieved the target for the millennium development goal(MDG) target on the reduction of child mortality. However, neonatal mortality is still alarming at the rate of 33 per 1000 live births and was relatively stagnant in the past decade [10]. A cross-sectional study from central Nepal in 2005 reported that $72.7 \%$ of recently delivered women initiated breastfeeding within the first hour of birth [11]. More recently, a community based prospective cohort study from central Nepal showed that about $67 \%$ mothers initiated breastfeeding within first hour after delivery [12]. A further analysis of the NDHS 2011 reported that about $27 \%$ of mothers provided prelacteal foods to their newborn babies [13]. That study found maternal education associated with the prelacteal feeding. Similarly, studies from abroad have found a positive association between maternal education status with the early initiation of breastfeeding $[14,15]$, exclusive breastfeeding practice [16-18] and the duration of breastfeeding [19]. However, early initiation of breastfeeding and the factors associated with early initiation remains understudied in Nepal.

Education status of the mother has been identified as an important social determinant of health for children. The role of maternal education on infant feeding behaviour is an interesting area to explore. Women's education in Nepal has long been neglected and still remains much lower than men. In recent years, there has been an improvement in women's education status. Therefore, the effect of maternal education might also impart effect on health and infant feeding behaviour. This study aims to investigate the association between early initiation of breastfeeding and mother's educational status using data from the Nepal Demographic and Health Survey 2001, 2006 and 2011.

\section{Methods}

The Nepal Demographic and Health Survey (NDHS) is a nationally representative population based survey conducted every 5 years since 1986. The NDHS implemented two stage cluster sampling. Firstly, the country was divided into sample domains and secondly sampling units were selected in each sample domain with probability proportional to size. The household was selected randomly from the sampling unit. The overall response rates of these surveys were high: NDHS 2001 (97.8\%), NDHS 2006 (98.0 \%) and NDHS 2011 (97.6 \%). Details of the sampling procedure are mentioned in the individual survey reports [20-22].
Child datasets of the NDHS 2001, 2006 and 2011 were appended for analysis. The datasets contained information about under 5 year old children, their parent and household characteristics. A total of 12,845 last born children born within 5 years before individual surveys were included in this study irrespective of their current status (living or dead). Since the time of initiation of breastfeeding is applicable to only those children who were reported to be breastfed at least once, children who were never breastfed were excluded from analysis.

\section{Definitions of variables}

WHO defines early initiation of breastfeeding as 'provision of mother's breast milk to infants within one hour of birth' [23]. During the survey mothers were asked - "How long after birth did you first put (name of the children) to the breast?"The answers were recorded in terms of hours and days after birth. For this analysis, a child breastfed immediately after the birth and within first hour of birth was coded as "1 (Early initiation)" otherwise "0 (Late initiation)" [1, 4].

The main explanatory variable was mother's education level which was recorded as: (i) no education (ii) primary education and (iii) secondary or higher education. Other independent variables were selected based on literature $[19,24]$. Place of residence was reported as (i) urban and (ii) rural. Ecological zone was classified according to the altitude as (i) Mountain (ii) Hill (iii) Terai. Administrative regions are the five north-south segments of the nation namely (i) eastern development region (ii) central development region (iii) western development region (iv) mid-western development region and (v) far-western development region. Mother's occupation was classified into 3 categories: (i) not working (ii) agriculture (iii) other paid jobs [24]. Father's education was recorded similar to mother's education. Religion was grouped into (i) Hindu and (ii) Others (Muslim, Buddhist, Christian). Ethnicity was firstly classified in to seven groups according to Nepal Demographic and Health Survey ethnicity classification [25] and was further grouped into four categories:(i) relatively advantaged (Brahmin/Chhetri) (ii) relatively disadvantaged (Janajati/Newar/Muslims) (iii) Disadvantaged (Dalits) and (iv) others (Madheshi and other unidentified) [25]. NDHS uses household assets to derive wealth index derived from principal component analysis [26] as a measure of socioeconomic status. This wealth score is then divided in to five quintiles (i) poorest (ii) poorer (iii) middle (iv) richer and (v) richest [22]. The mother's age was grouped into three categories (i) $<20$ year (ii) $25-34$ years (iii) $>=35$ years. The sex of the child was grouped as: (i) male (ii) female. Birth order was recoded as: (i) first (ii) second (iii) third or more. Size at birth was based on the mother's perception of the size of child at birth which was recorded 
as:(i) very small/small (ii) average or (iii) large/very large [13]. Variable multiple births is a dummy for twins/triplets. Place of delivery was classified as: (i) home (ii) health facility (government or private facilities) (iii) other places. Mode of delivery was recorded as: (i) caesarean (ii) vaginal.

The DHS are conducted in more than 50 countries, mostly in low and middle income countries, and serve as a major source of policy making in those contexts. A generic question was first prepared by measure DHSprogram and modified according to country specific context. In Nepal, the questionnaire was pre-tested and validated before the survey. More detail on the questionnaire can be found elsewhere [20-22, 27].

\section{Statistical analysis}

We adopted the conceptual framework from Matanda et al. [28] with some modifications (see Fig. 1) to facilitate our statistical analyses. This conceptual framework was originally based on the model developed by the United Nations Children's Fund (UNICEF) and extended by Engle et al. [29]. The variables were grouped in to context, socio-economic and child specific demographic/health care variables according to their proximity to the dependent variable. We assumed that proximate variables have more direct effect than the distant variables. Statistical analysis was based on the survey analysis technique adjusting for weights assigned for non-response (sample weight) and cluster sampling design. Descriptive analysis was performed for sample background characteristics, followed by a logistic regression analysis to assess the association between mother's education status and early initiation of breastfeeding, based on the conceptual framework. Context variables (urban/rural, ecological zone and administrative regions) were adjusted in model1. In model-2; socioeconomic variables (mother's occupation, fathers' education status, religion, ethnicity, wealth quintile) and in model-3 child specific demographic and health care related variables (mother's age, ANC utilization, sex of child, birth order of the child, the size of the child at birth, multiple birth, place of delivery, mode of delivery) were adjusted respectively. Variables found significant in the previous model $(P<0.05)$ were additionally adjusted in succeeding models until the final model (model-4) was obtained with all the significant variables by following the conceptual framework [30].

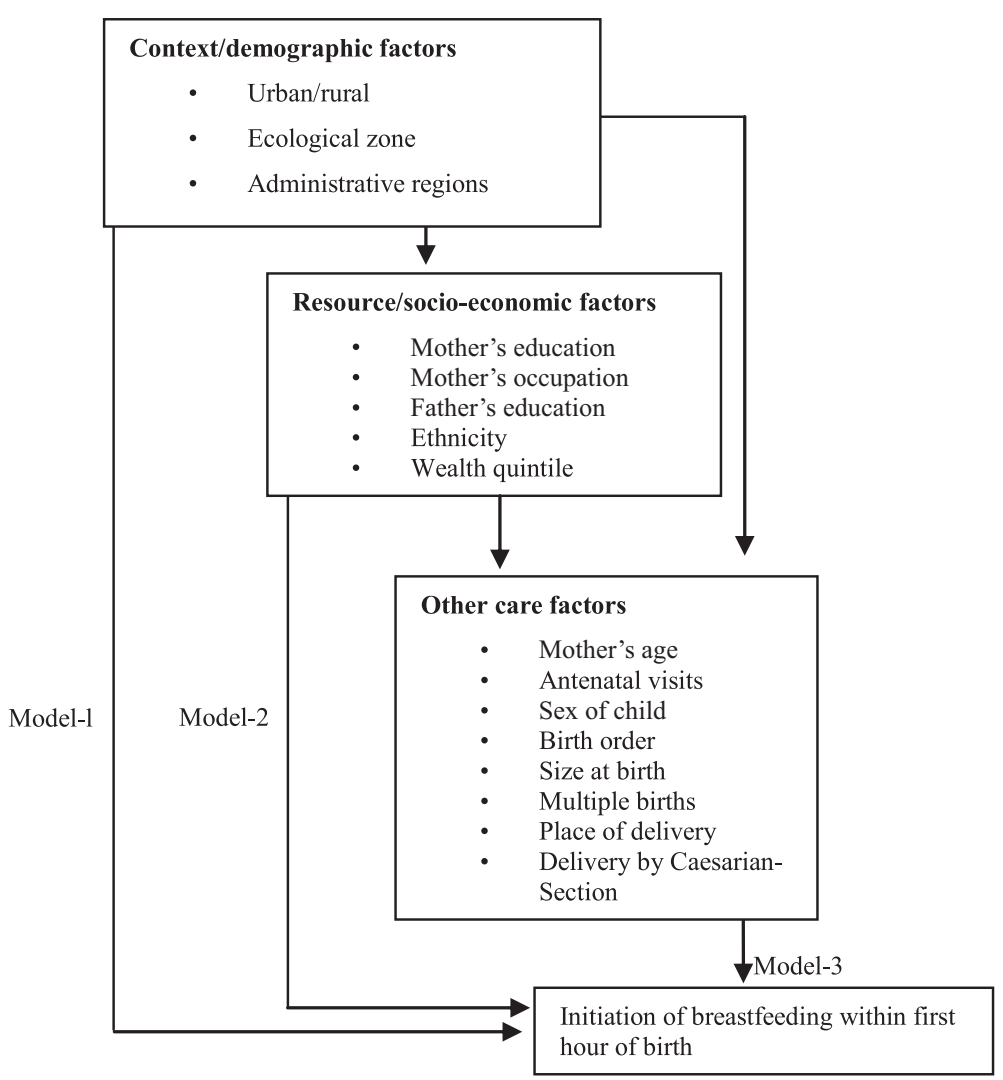

Fig. 1 Conceptual framework of determinants of early initiation of breastfeeding, prepared for hierarchical logistic regression modeling. Based on the model developed by UNICEF and extended by Engle et al [28]. Adopted and from Matanda et al [29] with some modification 
We checked the interaction term 'survey year*mother's education' to assess the change in mother's education status between the surveys, which was significant at $p<0.001$. Therefore, independent analyses were also performed for each survey 2001, 2006 and 2011. $P$-value $<0.05$ was considered statistically significant. Statistical analysis was performed in STATA 13.0.

\section{Ethics}

NDHS obtained ethical approval from the Nepal Health Research Council, Kathmandu, Nepal and Macro Institutional Review Board, Maryland, USA [20-22]. NDHS obtained consent from mothers and their children before starting the interview. Permission to use the survey data for this study was granted by the Measure DHS program [27].

\section{Results}

\section{Characteristics of respondents}

The result represents a total of 12,845 mother-child pairs from demographic and health surveys. The majority of the respondents (58.68\%) had no education, about $17.50 \%$ had primary and $23.82 \%$ had a secondary or higher level education (see Fig. 2). Nearly nine in every ten respondents were from rural areas, more than half (51.01\%) were from Terai/plain land and about $31.93 \%$ were from the central development region. About three quarters $(75.33 \%)$ of mothers were working in the agriculture sector. The majority of the children (61.29\%) were born from the mothers of age group 20-34 years. Only about $21.97 \%$ children were delivered in a health facility (Table 1).

\section{Percentage of children breastfed within the first hour after birth}

The pooled data showed that slightly more than one third $(36.77 \%$, $95 \%$ CI: 35.79, 37.75) of the children were breastfed within the first hour after birth. Such an early initiation was higher for 2011 (44.49\%, $95 \%$ CI: $42.65,46.34)$ compared to 2006 (35.26 \% $95 \%$ CI: 33.45, 37.11 ) and 2001 (31.27 \%, 95 \% CI: 29.88, 32.69) (see Fig. 3). The difference in the percentage of women initiating breastfeeding within first after birth was statistically significant $(P<0.001)$ during the survey periods. The proportion of early initiation from pooled estimation was found to increase with increase in level of education. Results from the pooled data showed that children from the mothers with at least secondary education were more likely to be breastfed within $1 \mathrm{~h}$ after birth (48.29\%) in comparison to mothers with no education (31.55 \%) and mothers with primary education (38.54 \%) (see Fig. 3). A similar pattern was found, according to the father's education status.

The percentage of newborn infants breastfed within the first hour after birth was higher among urban $(41.44 \%)$ areas in comparison to rural areas and the hill region (40.29\%) compared to the mountain or Terai region. Similarly, babies from the mothers with paid jobs, whose fathers had higher education, from the Hindu religion, from the advantaged ethnic group; from higher wealth quintiles had higher rates of early initiation of breastfeeding. The percentage of early breastfeeding was higher among the babies from mothers of age 20-34 years, mothers who completed four antenatal care visits, babies born in the second in order, babies average or larger in size at birth and babies delivered in a health facility. The proportion of early breastfed babies was lower among the multiple

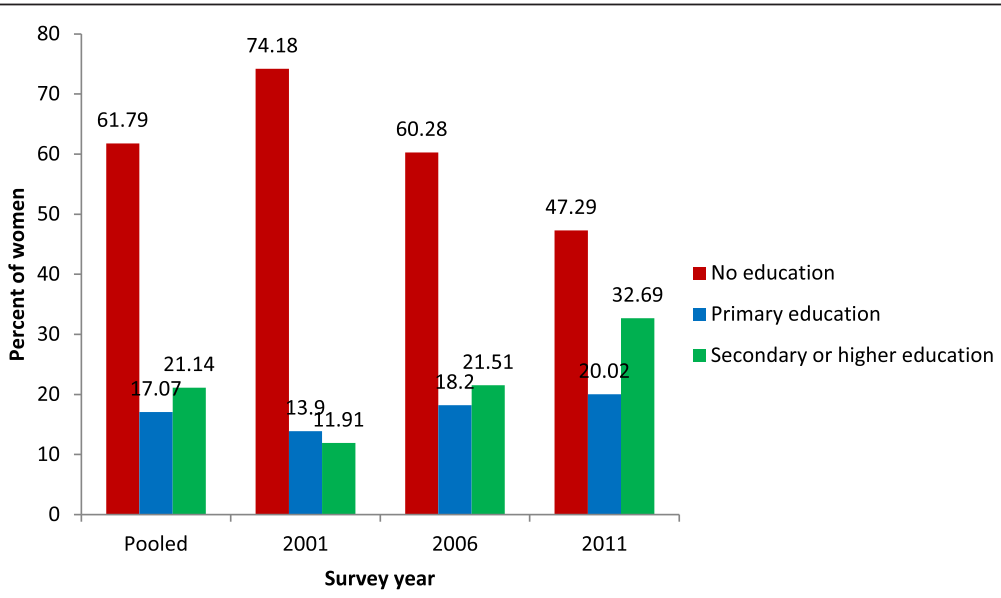

Fig. 2 Percentage of ever breastfed women gave birth within 5 years before the survey according to their education status (NDHS 2001,2006 and 2011) 
Table 1 Percentage of newborn babies breastfed within the first hour of birth according to the background characteristics. Children born within 5 years before the surveys NDHS 2001, 2006 and 2011

\begin{tabular}{|c|c|c|c|c|c|c|}
\hline \multirow[t]{2}{*}{ Characteristics } & \multirow{2}{*}{$\begin{array}{l}\text { Total }^{a} \\
\%\end{array}$} & \multirow{2}{*}{$\begin{array}{l}\text { Pooled }(n=12,845) \\
\text { (n) }\end{array}$} & \multirow{2}{*}{$\begin{array}{l}\text { NDHS } 2011(n=4116) \\
\% \text { early breastfed }\end{array}$} & \multirow{2}{*}{$\begin{array}{l}\text { NDHS } 2006(n=4051) \\
\% \text { early breastfed }\end{array}$} & \multicolumn{2}{|c|}{ NDHS $2001(n=4678)$} \\
\hline & & & & & $\%$ early breastfed & $\%$ early breastfed \\
\hline \multicolumn{7}{|l|}{ Survey year } \\
\hline 2001 & 36.42 & 4678 & 31.27 & & & \\
\hline 2006 & 31.54 & 4051 & 35.26 & & & \\
\hline 2011 & 32.05 & 4116 & 44.49 & & & \\
\hline \multicolumn{7}{|l|}{ Mother's education } \\
\hline No education & 58.68 & 7537 & 31.55 & 34.42 & 31.54 & 30.04 \\
\hline Primary & 17.5 & 2248 & 38.54 & 45.1 & 37.38 & 31.69 \\
\hline Secondary/higher & 23.82 & 3060 & 48.29 & 56.33 & 42.73 & 37.57 \\
\hline \multicolumn{7}{|l|}{ Place of residence } \\
\hline Urban & 9.89 & 1270 & 41.44 & 48.42 & 39.44 & 35.89 \\
\hline Rural & 90.11 & 11,575 & 36.25 & 44.05 & 34.63 & 30.92 \\
\hline \multicolumn{7}{|l|}{ Ecological zone } \\
\hline Mountain & 7.79 & 1001 & 37.62 & 47.82 & 31.26 & 35.01 \\
\hline Hill & 41.2 & 5292 & 40.29 & 46.91 & 32.65 & 41.24 \\
\hline Terai & 51.01 & 6552 & 33.78 & 42.16 & 38.08 & 22.44 \\
\hline \multicolumn{7}{|l|}{ Development region } \\
\hline Eastern & 22.97 & 2950 & 36 & 48.28 & 32.84 & 27.35 \\
\hline Central & 31.93 & 4101 & 26.65 & 34.86 & 33.6 & 13.6 \\
\hline Western & 19.29 & 2478 & 38.88 & 49.08 & 35.61 & 32.38 \\
\hline Mid-western & 13.98 & 1796 & 48.62 & 45 & 32.38 & 63.85 \\
\hline Far-western & 11.83 & 1520 & 48.08 & 54.73 & 44.7 & 46.23 \\
\hline \multicolumn{7}{|l|}{ Mother's occupation } \\
\hline Not working & 20.84 & 2677 & 35.35 & 42.59 & 38.07 & 21.65 \\
\hline Agriculture & 75.33 & 9676 & 36.88 & 44.61 & 34.15 & 33.25 \\
\hline Paid Jobs & 3.83 & 492 & 42.29 & 58.85 & 41.87 & 30.91 \\
\hline \multicolumn{7}{|l|}{ Father's education } \\
\hline No education & 26.74 & 3435 & 29.23 & 31.27 & 32.83 & 26.05 \\
\hline Primary & 25.69 & 3300 & 34.99 & 41.1 & 33.01 & 31.81 \\
\hline Above secondary & 46.41 & 5961 & 42.34 & 51.09 & 37.94 & 36.02 \\
\hline Don't know & 1.16 & 149 & 26.49 & 34.21 & 25.9 & 24.96 \\
\hline \multicolumn{7}{|l|}{ Ethnicity } \\
\hline Advantaged & 29.99 & 3852 & 43.24 & 51.18 & 33.21 & 44.92 \\
\hline Relatively disadvantaged & 41.07 & 5275 & 38.71 & 45.32 & 40.87 & 30.57 \\
\hline Disadvantaged & 15.52 & 1994 & 33.65 & 38.77 & 31.4 & 30.71 \\
\hline Madheshi and others & 13.42 & 1724 & 19.95 & 29.85 & 27.03 & 9.41 \\
\hline \multicolumn{7}{|l|}{ Wealth quintile } \\
\hline Poorest & 20.91 & 2686 & 32.44 & 38.12 & 29.73 & 28.52 \\
\hline Poorer & 20.55 & 2640 & 35.86 & 40.32 & 37.59 & 29.6 \\
\hline Middle & 19.41 & 2493 & 37.57 & 43.05 & 34.68 & 34.71 \\
\hline Richer & 19.63 & 2521 & 37.71 & 50.88 & 34.98 & 30.24 \\
\hline Richest & 19.49 & 2503 & 40.61 & 54.47 & 41.1 & 32.76 \\
\hline
\end{tabular}


Table 1 Percentage of newborn babies breastfed within the first hour of birth according to the background characteristics. Children born within 5 years before the surveys NDHS 2001, 2006 and 2011 (Continued)

\begin{tabular}{|c|c|c|c|c|c|c|}
\hline \multicolumn{7}{|l|}{ Age of mother } \\
\hline $14-19$ years & 7.96 & 1022 & 36.06 & 45.26 & 39.54 & 24.65 \\
\hline 20-34 years & 61.29 & 7873 & 38.26 & 46.84 & 35.66 & 32.39 \\
\hline $35-49$ years & 30.75 & 3950 & 33.97 & 39.03 & 33.16 & 30.9 \\
\hline \multicolumn{7}{|l|}{ ANC visit } \\
\hline No Visits & 31.71 & 4053 & 31.59 & 33.51 & 28.49 & 32.47 \\
\hline $1-3$ visits & 37.71 & 4820 & 33.87 & 38.36 & 36.36 & 27.21 \\
\hline 4 or more & 30.59 & 3910 & 45.92 & 52.33 & 40.04 & 36.64 \\
\hline \multicolumn{7}{|l|}{ Sex of child } \\
\hline Male & 51.79 & 6652 & 37.03 & 44.98 & 35.39 & 31.11 \\
\hline Female & 48.21 & 6193 & 36.48 & 43.94 & 35.12 & 31.42 \\
\hline \multicolumn{7}{|l|}{ Birth order of child } \\
\hline First & 26.01 & 3341 & 38.46 & 47.12 & 37.65 & 27.81 \\
\hline Second & 25.8 & 3314 & 41.14 & 50.11 & 37.93 & 34.74 \\
\hline Third or more & 48.19 & 6190 & 33.51 & 38.63 & 32.25 & 31.15 \\
\hline \multicolumn{7}{|l|}{ Multiple birth } \\
\hline Single birth & 98.8 & 12,691 & 36.96 & 44.82 & 35.53 & 31.31 \\
\hline Multiple births & 1.2 & 154 & 20.95 & 21.63 & 18.14 & 25.31 \\
\hline \multicolumn{7}{|l|}{ Size at birth } \\
\hline Very small/small & 59.51 & 7644 & 35.84 & 43.96 & 33.79 & 29.23 \\
\hline Average & 18.62 & 2392 & 35.84 & 42.67 & 31.64 & 34.63 \\
\hline Larger & 21.81 & 2801 & 40.03 & 47.82 & 41.81 & 33.04 \\
\hline \multicolumn{7}{|l|}{ Place of delivery } \\
\hline Home & 76.35 & 9807 & 33.82 & 37.97 & 34.2 & 31.05 \\
\hline Health facility & 21.97 & 2822 & 47.72 & 55.11 & 39.68 & 35.45 \\
\hline Others & 1.67 & 215 & 27.37 & 31.02 & 33.6 & 21.44 \\
\hline \multicolumn{7}{|l|}{ Mode of delivery } \\
\hline Vaginal & 96.93 & 12,451 & 37.22 & 45.46 & 35.87 & 31.4 \\
\hline Caesarean & 3.07 & 394 & 22.56 & 27.04 & 16.14 & 19.42 \\
\hline
\end{tabular}

${ }^{a}$ numbers and percentages after adjusting for sample weight and cluster sampling design

births and caesarean delivery compared to babies delivered by vaginal delivery. Detail comparison of proportions is presented in Table 1 .

\section{Association between maternal education and early initiation of breastfeeding}

Table 2 shows the results of bivariate and multivariate analysis adjusted for relevant variables. The table shows the results from the final model (model 4, according to conceptual framework) of logistic regression analysis for pooled data, data from NDHS 2011, NDHS 2006 and NDHS 2001. Pooled data provides us the higher power to detect the statistical association, if there is any. It also allows us to calculate narrow confidence intervals because of the larger sample size. The results of the logistic regression analysis using pooled data showed higher odds of early initiation of breastfeeding among children from the mothers with primary education [OR: 1.24; $95 \%$ CI: $1.08,1.42]$, and secondary or higher education [OR: $1.63 ; 95 \%$ CI: $1.42,1.88$ ] compared to the children from mothers with no education (Table 2).

We assessed the interaction term between the mother's education and survey year, in the multivariate adjusted model, since the interaction was significant ( $p$ $<0.001$ ) we developed separate models for individual survey 2011; 2006, and 2001. In 2011, odds of early initiation of breastfeeding was higher among mothers with primary education [OR: 1.52; $95 \% \mathrm{CI}: 1.21,1.91$ ] and secondary or higher education [OR: 2.20; $95 \% \mathrm{CI}: 1.76$, 2.76] compared to those with no education. In 2006, it was also higher among mothers with secondary or 


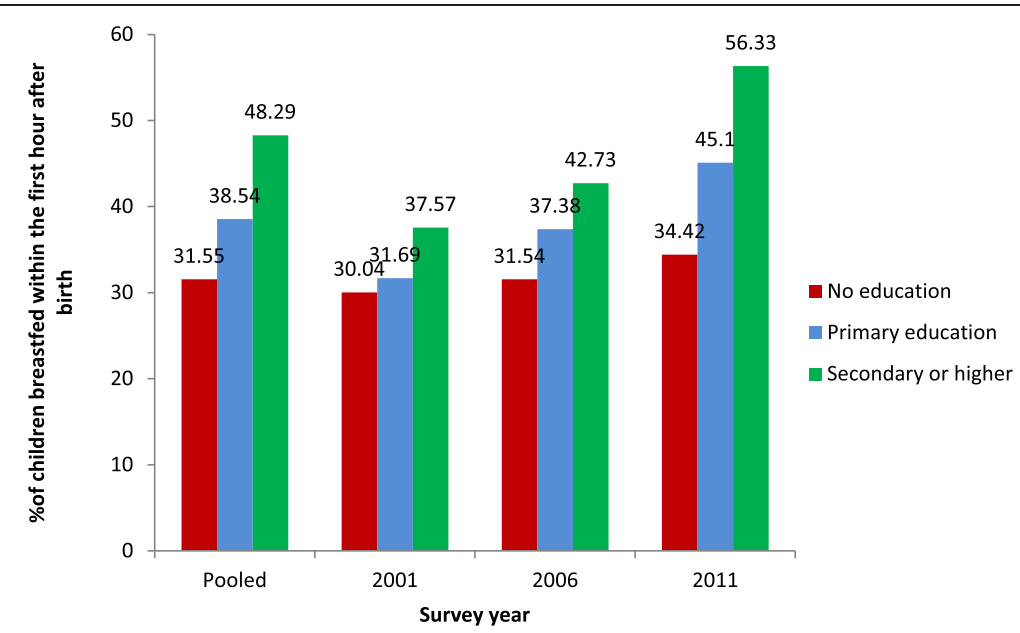

Fig. 3 Percentage of last born children born within 5 years before the survey breastfed within the first hour after birth according to mother's education status and survey year (NDHS 2001, 2006 and 2011)

higher education [OR: 1.66; 95 \% CI: 1.30, 2.12]. In 2001, having a secondary or higher education was marginally significant $[\mathrm{OR}=1.30 ; 95 \% \mathrm{CI} 1.00,1.67 ; p=0.05]$. These models showed that there was increased likelihood of early initiation of breastfeeding with increasing maternal education.

This analysis found other characteristics independently associated with early initiation of breastfeeding, after controlling for the effect of mother's education. The groups who had a higher likelihood of early initiation were the mothers who were from mid-western and farwestern regions, from higher wealth quintile, who had four antenatal care visits, were second parity mothers, had larger babies, and had delivered in health facilities. Conversely, mothers who were from the Terai (plain) region, rural areas, from madheshi and other ethnic group, had multiple births and had delivered via caesarean section had a lower likelihood of early initiation of breastfeeding. (Details are shown in the Additional file 1).

\section{Discussion}

This study found newborn babies from the mothers with primary education and secondary or higher education were more likely to be breastfed within the first hour after birth in comparison to the babies from the mothers with no education. We found a significant increase in the percentage of early initiation of breastfeeding during three surveys. National nutrition policy and strategy 2004 and its amendment in 2008 have given special emphasis on breastfeeding promotion including early initiation of breastfeeding [31], also mentioned in the MultiSectoral Nutrition Plan (2013-2017) [32]. Community based newborn care program (CB-NCP) implemented by the government directly advocates for the initiation of breastfeeding within first hour after birth [33, 34].
The government has promoted Baby Friendly Hospital Initiative [35-37]. Public awareness campaigns via mass media might also have impacted to this increase in early initiation of breastfeeding. A recent study conducted in central Nepal reported that about $67 \%$ of recently delivered mothers breastfed their newborns within the first hour of birth [12]. A cross sectional survey conducted in an urban city of western Nepal in 2006 found that about $58 \%$ mothers initiated breastfeeding their babies within first hour after birth [38]. These studies reported higher rates of early initiation than the NDHS and the difference can be accounted for in varied study settings and methodology. This study confirms the positive role of mother's education to early initiation of breastfeeding. The association between mother's education and early initiation of breastfeeding was at a marginal significance level for mothers with secondary or higher education in 2001 and was statistically significant in 2006. Meanwhile, the association was more prominent for the latest 2011 survey. This shows the increasing importance of education for uptake of 'messages' about breastfeeding that emerged in government policy and various national programmes in between the survey periods. An observational study from Bangladesh reported that caretakers with formal education were more likely to feed their babies more frequently, feed hygienic foods in a hygienic environment [39]. A review of literature had reported maternal education as a consistently associated demographic factor with early initiation of breastfeeding [19]. A systematic review of interventions designed to promote exclusive breastfeeding in high income countries found that the interventions using educational approaches were significantly associated to the increase in the duration of exclusive breastfeeding [40, 41]. Educating and counselling mothers have found as a successful 
Table 2 Association between mother's education status and initiation of breastfeeding within one hour after birth. Hierarchical modelling by using logistic regression analysis (pooled data, NDHS 2011, NDHS 2006 and NDHS 2001)

\begin{tabular}{|c|c|c|c|c|c|c|c|c|c|c|c|c|c|c|c|c|c|c|c|c|}
\hline \multirow{3}{*}{$\frac{\text { Characteristics }}{\text { Mother's education }}$} & \multicolumn{4}{|c|}{$\begin{array}{l}\text { Unadjusted } \\
\text { from pooled analysis }\end{array}$} & \multicolumn{4}{|c|}{$\begin{array}{l}\text { Pooled } \\
\text { Model }^{a}\end{array}$} & \multicolumn{4}{|c|}{$2011^{\mathrm{b}}$} & \multicolumn{4}{|c|}{$2006^{c}$} & \multicolumn{4}{|c|}{$2001^{d}$} \\
\hline & \multirow[t]{2}{*}{$\overline{O R}$} & \multicolumn{2}{|c|}{$(95 \% \mathrm{Cl})$} & \multirow[t]{2}{*}{$P$-value } & \multirow[t]{2}{*}{ OR } & \multicolumn{2}{|c|}{$(95 \% \mathrm{Cl})$} & \multirow[t]{2}{*}{$P$-value } & \multirow[t]{2}{*}{ OR } & \multicolumn{2}{|c|}{$(95 \%$ Cl) } & \multirow[t]{2}{*}{$P$-value } & \multirow[t]{2}{*}{ OR } & \multicolumn{2}{|c|}{$(95 \% \mathrm{Cl})$} & \multirow[t]{2}{*}{$P$-value } & \multirow[t]{2}{*}{ OR } & \multicolumn{2}{|c|}{$(95 \% \mathrm{Cl})$} & \multirow[t]{2}{*}{$P$-value } \\
\hline & & & & & & & & & & & & & & & & & & & & \\
\hline No education & 1.00 & & & & 1.00 & & & & 1.00 & & & & 1.00 & & & & 1.00 & & & \\
\hline Primary & 1.36 & $(1.20$ & $1.54)$ & 0.000 & 1.24 & $(1.09$ & 1.42) & 0.002 & 1.52 & $(1.21$ & 1.91) & 0.000 & 1.24 & $(0.96$ & 1.60) & 0.093 & 1.07 & $(0.87$ & 1.32) & 0.506 \\
\hline Above secondary & 2.03 & $(1.79$ & 2.30) & 0.000 & 1.63 & $(1.42$ & $1.88)$ & 0.000 & 2.20 & $(1.76$ & $2.76)$ & 0.000 & 1.66 & $(1.30$ & 2.12) & 0.000 & 1.30 & $(1.00$ & 1.70) & 0.052 \\
\hline \multicolumn{21}{|l|}{ Place of residence } \\
\hline Urban & 1.00 & & & & & & & & & & & & & & & & 1.00 & & & \\
\hline Rural & 0.80 & $(0.70$ & $0.92)$ & 0.002 & & & & & & & & & & & & & 0.74 & $(0.58$ & $0.93)$ & 0.012 \\
\hline \multicolumn{21}{|l|}{ Ecological zone } \\
\hline Mountain & 1.00 & & & & & & & & & & & & & & & & 1.00 & & & \\
\hline Hill & 1.12 & $(0.96$ & 1.30) & 0.149 & & & & & & & & & & & & & 1.25 & $(1.02$ & 1.53) & 0.030 \\
\hline Terai & 0.85 & $(0.71$ & $1.01)$ & 0.062 & & & & & & & & & & & & & 0.74 & 0.58 & $0.94)$ & 0.013 \\
\hline Development region & & & & & & & & & & & & & & & & & & & & \\
\hline Eastern & 1.00 & & & & 1.00 & & & & 1.00 & & & & 1.00 & & & & 1.00 & & & \\
\hline Central & 0.65 & $(0.55$ & $0.76)$ & 0.000 & 0.72 & $(0.62$ & $0.83)$ & 0.000 & 0.65 & $(0.47$ & $0.91)$ & 0.012 & 1.12 & $(0.90$ & 1.40) & 0.317 & 0.42 & $(0.34$ & $0.53)$ & 0.000 \\
\hline Western & 1.13 & $(0.94$ & 1.37) & 0.202 & 1.11 & $(0.93$ & 1.33) & 0.262 & 1.01 & $(0.73$ & 1.40) & 0.958 & 1.14 & $(0.81$ & 1.60) & 0.456 & 1.14 & $(0.83$ & 1.56) & 0.428 \\
\hline Mid-western & 1.68 & $(1.39$ & 2.03) & 0.000 & 1.98 & $(1.63$ & 2.41) & 0.000 & 1.03 & $(0.75$ & 1.42) & 0.852 & 1.24 & $(0.90$ & 1.71) & 0.188 & 4.42 & $(3.10$ & 6.29) & 0.000 \\
\hline Far-western & 1.65 & $(1.27$ & 2.13) & 0.000 & 1.92 & $(1.49$ & 2.48) & 0.000 & 1.53 & $(1.09$ & $2.15)$ & 0.014 & 1.97 & $(1.25$ & $3.10)$ & 0.004 & 2.14 & $(1.64$ & 2.79) & 0.000 \\
\hline Ethnicity & & & & & & & & & & & & & & & & & & & & \\
\hline Advantaged & 1.00 & & & & 1.00 & & & & & & & & 1.00 & & & & 1.00 & & & \\
\hline Relatively disadvantaged & 0.83 & $(0.72$ & $0.96)$ & 0.011 & 1.21 & $(1.04$ & 1.41) & 0.013 & & & & & 1.71 & $(1.29$ & 2.26) & 0.000 & 1.12 & $(0.87$ & 1.45) & 0.366 \\
\hline Disadvantaged & 0.67 & $(0.57$ & $0.78)$ & 0.000 & 0.94 & $(0.80$ & 1.10) & 0.435 & & & & & 1.20 & $(0.89$ & $1.61)$ & 0.224 & 0.86 & $(0.69$ & $1.07)$ & 0.168 \\
\hline Madheshi and others & 0.33 & $(0.26$ & $0.42)$ & 0.000 & 0.60 & $(0.47$ & $0.76)$ & 0.000 & & & & & 0.99 & $(0.68$ & 1.44) & 0.963 & 0.49 & $(0.28$ & $0.83)$ & 0.009 \\
\hline Wealth quintile & & & & & & & & & & & & & & & & & & & & \\
\hline Poorest & 1.00 & & & & 1.00 & & & & & & & & 1.00 & & & & 1.00 & & & \\
\hline Poorer & 1.16 & $(1.01$ & 1.34) & 0.036 & 1.21 & $(1.04$ & 1.41) & 0.015 & & & & & 1.42 & $(1.09$ & 1.86) & 0.010 & 0.96 & $(0.77$ & 1.21) & 0.746 \\
\hline Middle & 1.25 & $(1.07$ & 1.47) & 0.006 & 1.27 & $(1.08$ & 1.50) & 0.003 & & & & & 1.18 & $(0.90$ & 1.57) & 0.231 & 1.11 & $(0.86$ & 1.43) & 0.432 \\
\hline Richer & 1.26 & $(1.06$ & $1.50)$ & 0.008 & 1.24 & $(1.04$ & 1.48) & 0.019 & & & & & 1.21 & $(0.86$ & 1.70) & 0.265 & 0.95 & $(0.73$ & $1.25)$ & 0.730 \\
\hline Richest & 1.42 & $(1.21$ & 1.68) & 0.000 & 1.24 & $(1.04$ & 1.47) & 0.017 & & & & & 1.45 & $(1.06$ & 1.99) & 0.022 & 1.03 & $(0.78$ & 1.35) & 0.845 \\
\hline ANC visit & & & & & & & & & & & & & & & & & & & & \\
\hline No visits & 1.00 & & & & 1.00 & & & & & & & & 1.00 & & & & 1.00 & & & \\
\hline
\end{tabular}


Table 2 Association between mother's education status and initiation of breastfeeding within one hour after birth. Hierarchical modelling by using logistic regression analysis (pooled data, NDHS 2011, NDHS 2006 and NDHS 2001) (Continued)

\begin{tabular}{|c|c|c|c|c|c|c|c|c|c|c|c|c|c|c|c|c|c|c|c|c|}
\hline $1-3$ visits & 1.11 & $(0.97$ & 1.26) & 0.122 & 1.07 & $(0.94$ & 1.21) & 0.302 & & & & & 1.36 & $(1.10$ & 1.67) & 0.004 & 0.95 & $(0.82$ & 1.11) & 0.530 \\
\hline 4 or more & 1.84 & $(1.58$ & 2.14) & 0.000 & 1.32 & $(1.12$ & 1.56) & 0.001 & & & & & 1.40 & $(1.04$ & 1.89) & 0.026 & 1.38 & $(1.07$ & 1.78) & 0.014 \\
\hline \multicolumn{21}{|l|}{ Birth order } \\
\hline First & 1.00 & & & & 1.00 & & & & 1.00 & & & & & & & & 1.00 & & & \\
\hline Second & 1.12 & $(0.99$ & 1.26) & 0.061 & 1.30 & $(1.15$ & 1.47) & 0.000 & 1.43 & $(1.15$ & 1.78) & 0.002 & & & & & 1.53 & $(1.23$ & 1.91) & 0.000 \\
\hline Third or more & 0.81 & $(0.72$ & $0.90)$ & 0.000 & 1.22 & $(1.08$ & 1.38) & 0.001 & 1.29 & $(1.02$ & 1.63) & 0.036 & & & & & 1.35 & $(1.14$ & $1.61)$ & 0.001 \\
\hline \multicolumn{21}{|l|}{ Size at birth } \\
\hline Small & 1.00 & & & & & & & & & & & & 1.00 & & & & & & & \\
\hline Average & 1.00 & $(0.89$ & 1.12) & 0.998 & & & & & & & & & 0.97 & $(0.77$ & $1.21)$ & 0.757 & & & & \\
\hline Larger & 1.19 & $(1.03$ & 1.38) & 0.017 & & & & & & & & & 1.33 & $(1.03$ & 1.71) & 0.027 & & & & \\
\hline Multiple births & 0.45 & $(0.25$ & $0.81)$ & 0.007 & 0.42 & $(0.23$ & $0.76)$ & 0.004 & 0.26 & $(0.08$ & $0.81)$ & 0.021 & 0.38 & $(0.13$ & 1.11) & 0.078 & & & & \\
\hline \multicolumn{21}{|l|}{ Place of delivery } \\
\hline Home & 1.00 & & & & 1.00 & & & & 1.00 & & & & & & & & 1.00 & & & \\
\hline Health facility & 1.79 & $(1.58$ & 2.02) & 0.000 & 1.73 & $(1.50$ & 2.01) & 0.000 & 2.09 & $(1.74$ & $2.50)$ & 0.000 & & & & & 1.39 & $(1.06$ & 1.82) & 0.018 \\
\hline Other place & 0.74 & $(0.54$ & 1.02) & 0.062 & 0.67 & $(0.47$ & $0.94)$ & 0.022 & 0.62 & $(0.33$ & 1.16) & 0.133 & & & & & 0.42 & $(0.23$ & $0.77)$ & 0.005 \\
\hline \multicolumn{21}{|l|}{ Mode of delivery } \\
\hline Vaginal & 1.00 & & & & 1.00 & & & & 1.00 & & & & 1.00 & & & & 1.00 & & & \\
\hline Caesarian & 0.49 & $(0.36$ & $0.67)$ & 0.000 & 0.27 & $(0.19$ & $0.38)$ & 0.000 & 0.24 & $(0.16$ & $0.36)$ & 0.000 & 0.24 & $(0.12$ & 0.48) & 0.000 & 0.40 & $(0.16$ & 0.99) & 0.047 \\
\hline
\end{tabular}

$O R$ odds ratio; $\mathrm{Cl}$ confidence interv

a Adjusted for- Mother's education, Development region, Ethnicity, Wealth quintile, ANC visit, Birth order, Multiple births, Place of delivery and Mode of delivery

${ }^{b}$ Adjusted for-Mother's education, Development region, Birth order, Multiple births, Place of delivery and Mode of delivery

' adjusted for -Mother's education, Development region, Ethnicity, Wealth quintile, ANC visits, Size at birth, Multiple births, Mode of delivery

${ }^{d}$ adjusted for-Mother's education, Place of residence, Ecological zone, Development region, Ethnicity, Wealth quintile, ANC visit, Birth order, Place of delivery and Mode of delivery 
intervention for early initiation and sustaining breastfeeding even in the complicated situation like caesarean section [42]. Taken together, the current findings of a consistent association of maternal education with early initiation of breastfeeding is comparable to international findings.

\section{Other significant factors associated with early initiation of breastfeeding}

It is worthwhile to discuss the other demographic and socio-economic characteristics identified as independently associated with the early initiation of breastfeeding. However, the primary objective of this paper was to investigate the association between mother's education and early initiation of breastfeeding.

Higher odds of early initiation of breastfeeding in the western and far western region can be explained by the concentrated effort of existing maternal and child health intervention programs in the recent years. It might also because of the unavailability or inaccessibility to the alternatives of breastfeeding in those regions.

The odds of early initiation were higher among higher wealth quintiles. Socio- economic deprivation has been identified as the predictor of breastfeeding duration elsewhere $[43,44]$. Higher wealth index was found positively associated with the greater likelihood of using recommended level of antenatal care visits [45], where they receive counselling about colostrum feeding. Wealthier mothers are also more likely to deliver at the health facility and receive postnatal care where they can get more support for breastfeeding initiation [46, 47], while poorest mothers are deprived from those advantages.

Higher odds of early initiation of breastfeeding among the babies delivered at health facilities can be explained by the presence of health professional, their monitoring and support for the breastfeeding, which assures mothers to start early initiation of breastfeeding. This study found a significant proportion of children delivered at health facility were still not breastfed within first hour after birth. A study reported found higher rate of early initiation of breastfeeding and better newborn care practices among the institutional delivery in Dhanusha district (from the Terai region) of Nepal [48]. However, the study also showed the scope for improvement on the early initiation of breastfeeding among institutional deliveries [48].

Similarly, large size babies are more likely to be full termed and healthier, they have better coordination of the suction-deglutition-respiration cycle and breast seeking reflex $[49,50]$. This explains why the large size babies are more likely to be early breastfed than small size babies.

Support from the family and society is important factor for successful breastfeeding. Women's knowledge about the benefit of breastfeeding and their perception plays an important role to initiate breastfeeding early. Women in rural areas are found to have low knowledge about the importance of breastfeeding and they are also less likely to get support for breastfeeding. Those factors might have resulted in lower odds of early initiation of breastfeeding in the rural areas [51]. Similarly, lower odds of early initiation of breastfeeding in the terai region may be associated with the cultural practices of introduction of prelacteal food in the region [13]. An earlier study from Rupandehi district of Nepal (from the terai region) also reported extremely low rate (3.4\%) of initiation of breastfeeding within the first hour after birth [9].

A study in southern Nepal, where most of the participants were from Madheshi ethnic group revealed that about two in five mothers discarded colostrum [52]. Such harmful cultural practices inhibit initiation of breastfeeding within first hour after birth; therefore we obtained lower odds of early initiation of breastfeeding among those ethnic groups.

It may be difficult for mothers to breastfeed early who are primi-parous, have multiple births and have a caesarean delivery to initiate breastfeeding within the first hour of birth. This may explain the lower odds of early initiation among caesarean deliveries [53-56]. Earlier studies have found parity associated with the breastfeeding behaviour $[57,58]$. Confidence of mother is also an important factors which determines the initiation of breastfeeding, which increases with the parity [56].

\section{Public health implications of the current findings}

The current findings have a number of public health implications. This study has demonstrated the importance of maternal education on early initiation of breastfeeding. Since, improving educational status of mothers is a long term agenda, immediate attention should be provided to mothers with no or less education with alternative supportive and educational interventions like prenatal education and counselling [59]. Midwives, other health professionals and nurses can play important role to encourage mothers for early initiation of breastfeeding [60].

This study is based on the three large, nationally representative population based Demographic and Health Surveys in Nepal. Large sample size ensures a high precision of the findings. NDHS used the standardized tools; therefore, the results are reliable and comparable with other developing countries. However, causal inference between maternal education level and early initiation of breastfeeding is limited due to the study being cross sectional. Similarly, maternal education here represents the formal education gained through schooling and it may not reflect the health literacy of the mothers. 
This study doesn't explain about the separate counselling or breastfeeding education provide to women during the antenatal or postnatal period, which might have impacted on the early initiation of breastfeeding. Counselling and breastfeeding education are the major components of antenatal care visit (ANC), which is however, included in this study. Also, there may be recall bias since this study is based on the interview with mothers who gave birth within 5 years before the survey.

\section{Conclusions}

Maternal education was associated with an early initiation of breastfeeding in the 2001, 2006 and 2011 studies. Mothers with higher education were more likely to initiate breastfeeding with the first hour of childbirth. Future interventions should focus on increasing girl's and women's education program through formal or nonformal education programs, respectively. While school education is feasible for a girl child, adult learning approaches using literacy programs for adults, counselling, peer educations using through peer education would be more suitable for adult women who did not have a chance to go to school during their childhood.

\section{Additional file}

Additional file 1: Detail results of the hierarchical modeling using logistic regression. (XLSX $35 \mathrm{~kb})$

\section{Abbreviations}

ANC: Antenatal Care; Cl: Confidence interval; NDHS: Nepal Demographic and Health Survey; OR: Odds ratio; WHO: World Health Organization.

\section{Competing interest}

The authors declare that they have no competing interests.

\section{Authors' contributions}

PA designed the study, performed the statistical analysis, interpreted the findings and wrote the first draft of the manuscript. VK contributed in design of concept of study, quided statistical analyses, interpretation of findings and contributed significantly in manuscript writing. Both authors contributed in revision and have agreed on the final version of the manuscript.

\section{Acknowledgements}

We express our gratitude to Measure DHS program for providing access to DHS datasets. Our sincere thanks go to all the mothers who were interviewed during the surveys. We are grateful to Jessica Ohland for grammatical corrections. We are thankful to the two reviewers for their constructive comments which substantially increased the quality of this paper.

\section{Funding}

No funding was available for this study.

\author{
Author details \\ ${ }^{1}$ Nepal Development Society, Bharatpur, Nepal. ${ }^{2}$ School of Public Health, \\ Curtin University, Perth, Australia.
}

Received: 24 August 2014 Accepted: 12 October 2015

Published online: 19 October 2015

\section{References}

1. WHO, UNICEF. Global strategy for infant and young child feeding. World Health Organization; Geneva. 2003.

2. Arimond M, Daelmans B, Dewey K. Indicators for feeding practices in children. Lancet. 2008;371(9612):541-2.

3. World Health Organization: Exclusive breastfeeding. http://www.who.int/ nutrition/topics/exclusive_breastfeeding/en/. Accessed 15 July 2014.

4. Daelmans B, Dewey K, Arimond M. New and updated indicators for assessing infant and young child feeding. Food Nutr Bull. 2009;30(2):S256

5. Hanson $L \AA$, Korotkova M. The role of breastfeeding in prevention of neonatal infection. Seminars in FETAL and NEONATAL. 2002;7(4):275-281.

6. Onalo R. Neonatal hypothermia in sub-Saharan Africa: a review. Niger J Clin Pract. 2013;16(2):129-38.

7. Khan J, Vesel L, Bahl R, Martines JC. Timing of breastfeeding initiation and exclusivity of breastfeeding during the first month of life: effects on neonatal mortality and morbidity-a systematic review and meta-analysis. Matern Child Health J. 2014;19:468-79.

8. Edmond KM, Zandoh C, Quigley MA, Amenga-Etego S, Owusu-Agyei S, Kirkwood BR. Delayed breastfeeding initiation increases risk of neonatal mortality. Pediatrics. 2006;117(3):e380-6.

9. Mullany LC, Katz J, Li YM, Khatry SK, LeClerq SC, Darmstadt GL, et al. Breast-feeding patterns, time to initiation, and mortality risk among newborns in southern Nepal. J Nutr. 2008;138(3):599-603.

10. Paudel D, Thapa A, Shedain PR, Paudel B. Trends and Determinants of Neonatal Mortality in Nepal: Further Analysis of the Nepal Demographic and Health Surveys, 2001-2011. In. Calverton, Maryland, USA: Nepal Ministry of Health and Population, New ERA, and ICF International; 2013.

11. Chandrashekhar $T$, Joshi H, Binu V, Shankar P, Rana M, Ramachandran U. Breast-feeding initiation and determinants of exclusive breast-feeding-a questionnaire survey in an urban population of western Nepal. Public Health Nutr. 2007;10(02):192-7.

12. Karkee $\mathrm{R}$, Lee $\mathrm{AH}$, Khanal $\mathrm{V}$, Binns $\mathrm{CW}$. Initiation of breastfeeding and factors associated with prelacteal feeds in Central Nepal. J Hum Lact. 2014;30:353-7.

13. Khanal V, Adhikari M, Sauer K, Zhao Y, Egata G, Berhane $Y$, et al. Factors associated with the introduction of prelacteal feeds in Nepal: findings from the Nepal demographic and health survey 2011. Int Breastfeed J. 2013;8(1):9.

14. Van Rossem L, Oenema A, Steegers EA, Moll HA, Jaddoe WW, Hofman A et al. Are starting and continuing breastfeeding related to educational background? The generation R study. Pediatrics. 2009;123(6):e1017-27.

15. Heck KE, Braveman P, Cubbin C, Chávez GF, Kiely JL. Socioeconomic status and breastfeeding initiation among California mothers. Public Health Rep. 2006;121(1):51.

16. Glassman ME, McKearney K, Saslaw M, Sirota DR. Impact of breastfeeding self-efficacy and sociocultural factors on early breastfeeding in an Urban, Predominantly Dominican Community. Breastfeed Med. 2014;9:301-7.

17. Traore M, Sangho H, Diagne MC, Faye A, Sidibe A, Kone K, et al. Factors associated with exclusive breastfeeding among mothers of children 24 months in Bamako. Sante Publique (Vandoeuvre-les-Nancy, France). 2013;26(2):259-65

18. Dubois L, Girard M. Social determinants of initiation, duration and exclusivity of breastfeeding at the population level: the results of the Longitudinal Study of Child Development in Quebec (ELDEQ 1998-2002). Can J Public Health. 2003;94:300-5.

19. Scott JA, Binns CW. Factors associated with the initiation and duration of breastfeeding: a review of the literature. Breastfeed Rev. 1999;7(1):5-16.

20. Ministry of Health [Nepal] NE, and ORC Macro. Nepal Demographic and Health Survey 2001. In. Calverton, Maryland, USA: Family Health Division, Ministry of Health, New ERA, and ORC Macro; 2002.

21. Ministry of Health and Population (MOHP) [Nepal] NE, and Macro International Inc. Nepal Demographic and Health Survey 2006. In. Kathmandu, Nepal: Ministry of Health and Population, New ERA, and Macro International Inc; 2007.

22. Ministry of Health and Population (MOHP) [Nepal] NE, Macro International Inc. Nepal demographic and health survey 2011. In. Kathmandu [Nepal]: Ministry of Health and Population (MOHP) [Nepal], New ERA and Macro International Inc; 2012

23. World Health Organization: Early initiation of breastfeeding. http://www. who.int/elena/titles/early_breastfeeding/en/. Accessed 15 July 2014. 
24. Khanal V, Sauer K, Zhao Y. Exclusive breastfeeding practices in relation to social and health determinants: a comparison of the 2006 and 2011 Nepal Demographic and Health Surveys. BMC Public Health. 2013;13(1):958.

25. Bennett L, Dahal DR, Govindasamy P. Caste ethnic and regional identity in Nepal: further analysis of the 2006 Nepal Demographic and Health Survey. 2008.

26. Vyas S, Kumaranayake L. Constructing socio-economic status indices: how to use principal components analysis. Health Policy Plan. 2006;21(6):459-68.

27. Demographic and Health Surveys. http://dhsprogram.com/Data/. Accessed 15 July 2014.

28. Matanda DJ, Mittelmark MB, Urke HB, Amugsi DA. Reliability of demographic and socioeconomic variables in predicting early initiation of breastfeeding: a replication analysis using the Kenya Demographic and Health Survey data. BMJ Open. 2014:4(6):e005194.

29. Engle PL, Menon P, Garrett $J$, Slack A. Urbanization and caregiving: a framework for analysis and examples from southern and eastern Africa. Environ Urban. 1997:9(2):253-70.

30. Victora CG, Huttly SR, Fuchs SC, Olinto M. The role of conceptual frameworks in epidemiological analysis: a hierarchical approach. Int J Epidemiol. 1997;26(1):224-7.

31. Ministry of Health and Population (MOHP) Nepal. National Nutrition Policy and Strategy. In. Edited by Services DoH. Kathmandu: Government of Nepal; 2004.

32. Minisry of Health and Population (MOHP) Nepal. Multi-sector Nutrition Plan (2013-2017): For Accelerating the Reduction of Maternal and Child Under-nutrition in Nepal. In. Kathmandu, Nepal: Government of Nepal, Nationl Planning Commission; 2012.

33. Government of Nepal: Assessment of the Community Based Newborn Care Package. In. Edited by Depart of Health Services, Child Health Division. Teku, Kathmandu: Government of Nepal, Ministry of Health and Popultaion; 2012.

34. Manandhar D, Osrin D, Shrestha B, Meskey N, Morrison J, Tumbahanghe K, et al. Community-based newborn care package (unofficial translation). Lancet. 2004;364:970-9.

35. WHO, UNICEF. Baby-Friendly Hospital Initiative: revised, updated and expanded for integrated care. 2009.

36. Saadeh R, Casanovas C. Implementing and revitalizing the Baby-Friendly Hospital Initiative. Food Nutr Bull. 2009;30(Supplement 2):225S-9S.

37. Kramer MS, Chalmers B, Hodnett ED, Sevkovskaya Z, Dzikovich I, Shapiro S, et al. Promotion of Breastfeeding Intervention Trial (PROBIT): a randomized trial in the Republic of Belarus. JAMA. 2001;285(4):413-20.

38. Sreeramareddy $C T$, Joshi HS, Sreekumaran BV, Giri S, Chuni N. Home delivery and newborn care practices among urban women in western Nepal: a questionnaire survey. BMC Pregnancy Childbirth. 2006;6(1):27.

39. Guldan GS, Zeitlin MF, Beiser AS, Super CM, Gershoff SN, Datta S. Maternal education and child feeding practices in rural Bangladesh. Soc Sci Med. 1993;36(7):925-35.

40. Khresheh $R$, Suhaimat $A$, Jalamdeh F, Barclay $L$. The effect of a postnatal education and support program on breastfeeding among primiparous women: a randomized controlled trial. Int J Nurs Stud. 2011;48(9):1058-65.

41. Skouteris H, Nagle C, Fowler M, Kent B, Sahota P, Morris H. Interventions designed to promote exclusive breastfeeding in high-income countries: a systematic review. Breastfeed Med. 2014;9(3):113-27.

42. Banapurmath C, Ramachandrappa S, Guruprasad G, Biradar SB. Is cesarean section a barrier to early initiation of breastfeeding? Indian Pediatr. 2013;50(11):1062-3.

43. Brown AE, Raynor P, Benton D, Lee MD. Indices of Multiple Deprivation predict breastfeeding duration in England and Wales. Eur J Public Health. 2009:20:231-5

44. Scotland I. Breastfeeding by deprivation and maternal age. Edinburgh: NHS National Services Scotland; 2006.

45. Joshi C, Torvaldsen S, Hodgson R, Hayen A. Factors associated with the use and quality of antenatal care in Nepal: a population-based study using the demographic and health survey data. BMC Pregnancy Childbirth. 2014;14(1):94.

46. Karkee R, Lee AH, Khanal V. Need factors for utilisation of institutional delivery services in Nepal: an analysis from Nepal Demographic and Health Survey, 2011. BMJ Open. 2014;4(3):e004372.

47. Nawal D, Goli S. Birth preparedness and its effect on place of delivery and post-natal check-ups in Nepal. PLoS One. 2013;8(5):e60957.

48. Pagel C, Prost A, Hossen M, Azad K, Kuddus A, Roy SS, et al. Is essential newborn care provided by institutions and after home births? Analysis of prospective data from community trials in rural South Asia. BMC Pregnancy Childbirth. 2014;14(1):99.
49. Vieira TO, Vieira GO, Giugliani ER, Mendes CM, Martins CC, Silva LR. Determinants of breastfeeding initiation within the first hour of life in a Brazilian population: cross-sectional study. BMC Public Health. 2010;10(1):760.

50. Walker M. Breastfeeding the late preterm infant. J Obstetr Gynecol Neonatal Nurs. 2008;37(6):692-701

51. Joshi SK, Barakoti B, Lamsal S. Colostrum Feeding: Knowledge, Attitude and Practice in Pregnant Women in a Teaching Hospital in Nepal. WebmedCentral MEDICAL EDUCATION 2012;3(8):WMC003601. doi:10.9754/ journal.wmc.2012.003601.

52. Odent P. Early infant feeding and neonatal survival in Nepal: breastfeeding, colostrum and discarding of the first milk. London: UCL (University College London); 2011.

53. Rowe-Murray HJ, Fisher JR. Baby friendly hospital practices: cesarean section is a persistent barrier to early initiation of breastfeeding. Birth. 2002;29(2):124-31.

54. Pérez-Escamilla R, Maulén-Radovan I, Dewey KG. The association between cesarean delivery and breast-feeding outcomes among Mexican women. Am J Public Health. 1996;86(6):832-6.

55. Zanardo V, Svegliado G, Cavallin F, Giustardi A, Cosmi E, Litta P, et al. Elective cesarean delivery: Does it have a negative effect on breastfeeding? Birth. 2010;37(4):275-9.

56. Smith $L$. Impact of birthing practices on the breastfeeding dyad. J Midwifery Womens Health. 2007:52(6):621-30.

57. Dewey KG, Nommsen-Rivers LA, Heinig MJ, Cohen RJ. Risk factors for suboptimal infant breastfeeding behavior, delayed onset of lactation, and excess neonatal weight loss. Pediatrics. 2003;112(3):607-19.

58. Bourgoin GL, Lahaie NR, Rheaume BA, Berger MG, Dovigi C, Picard L, et al. Factors influencing the duration of breastfeeding in the Sudbury region. Can J Public Health. 1996;88(4):238-41.

59. Rosen IM, Krueger MV, Carney LM, Graham JA. Prenatal breastfeeding education and breastfeeding outcomes. MCN Am J Matern Child Nurs. 2008;33(5):315-9.

60. Swanson $\mathrm{V}$, Power KG. Initiation and continuation of breastfeeding: theory of planned behaviour. J Adv Nurs. 2005;50(3):272-82.

\section{Submit your next manuscript to BioMed Central and take full advantage of:}

- Convenient online submission

- Thorough peer review

- No space constraints or color figure charges

- Immediate publication on acceptance

- Inclusion in PubMed, CAS, Scopus and Google Scholar

- Research which is freely available for redistribution 